TITLE:

\title{
How do auroral substorms depend on Earth's dipole magnetic moment?
}

\author{
$\operatorname{AUTHOR}(\mathrm{S})$ :
}

Ebihara, Yusuke; Tanaka, Takashi

\section{CITATION:}

Ebihara, Yusuke ... [et al]. How do auroral substorms depend on Earth's dipole magnetic moment?. Journal of Geophysical Research: Space Physics 2021, 126(1): e2020 JA028009.

\section{ISSUE DATE:}

2021-01

URL:

http://hdl.handle.net/2433/267745

\section{RIGHT:}

(c) 2020. American Geophysical Union. All Rights Reserved.; The full-text file will be made open to the public on 29 May 2021 in accordance with publisher's 'Terms and Conditions for Self-Archiving'. 


\section{JGR Space Physics}

\section{RESEARCH ARTICLE \\ 10.1029/2020JA028009 \\ Key Points: \\ - MHD simulation is used to investigate the evolution of substorm under different Earth's dipole magnetic moment $M$ \\ - For lower $M$, expansion onset takes place later, auroral electrojet develops slowly, and the maximum auroral electrojet increases \\ - For lower $M$, auroral oval shifts equatorward during the growth phase and expands more equatorward and poleward during the expansion phase}

Supporting Information:

- Figure S1

Correspondence to:

Y. Ebihara,

ebihara@rish.kyoto-u.ac.jp

Citation:

Ebihara, Y., \& Tanaka, T. (2021). How do auroral substorms depend on Earth's dipole magnetic moment?. Journal of Geophysical Research: Space Physics, 126, e2020JA028009. https://doi. org/10.1029/2020JA028009

Received 13 MAR 2020 Accepted 29 OCT 2020

\section{How Do Auroral Substorms Depend on Earth's Dipole Magnetic Moment?}

\author{
Yusuke Ebihara $^{1}$ (1) and Takashi Tanaka ${ }^{2}$ (1) \\ ${ }^{1}$ Research Institute for Sustainable Humanosphere, Kyoto University, Uji, Japan, ${ }^{2}$ International Center for Space \\ Weather Science and Education, Kyushu University, Fukuoka, Japan
}

\begin{abstract}
Earth's dipole magnetic moment $M$ is known to decrease by 9\% over the past 150 years. It has been argued that the decrease in $M$ makes the near-Earth space environment different. We investigated how the change in $M$ affects the development of an auroral substorm by increasing and decreasing $M$ by a factor of 1.5 in global magnetohydrodynamics simulation. The ionospheric conductivity decreases with increasing $M$, in accordance with the aid of empirical relations. When we imposed the southward interplanetary magnetic field, an auroral substorm took place regardless of $M$, but its development depends largely on $M$. When $M$ is lower, (1) the expansion onset takes place later, (2) the auroral electrojet develops slowly, and (3) the maximum auroral electrojet increases. The first two consequences are probably associated with the slow magnetospheric convection as manifested by the polar cap potential drop. The third consequence is associated with the nonlinear dependence of substorm-associated field-aligned currents (FACs) on the ionospheric conductivity. The maximum values of the westward auroral electrojet and the net FACs increase with decreasing $M$, whereas the incident magnetic energy into the magnetosphere decreases with decreasing $M$. This implies that the efficiency of the generation of the substorm-associated FACs increases with decreasing $M$. It is also found that, for the lower $M$-value, the auroral oval shifts equatorward during the growth phase and expands more equatorward and poleward during the expansion phase. Evolution of substorms depends largely on the value of Earth's dipole moment and the ionospheric conductivity.
\end{abstract}

Plain Language Summary Earth's intrinsic magnetic field inhibits the direct entry of the fast streaming gas coming from the Sun, known as solar wind. Observations have shown that Earth's magnetic field has decreased by 9\% over the past 150 years. The reduction of Earth's magnetic field may make the near-Earth space environment different. Here, we show simulation results of auroral substorm under different strengths of Earth's magnetic field. The auroral substorm is one of the drastic, transient phenomena taking place in near-Earth space environment, which is accompanied with sudden brightening of aurora and sudden intensification of electrojet flowing in the upper atmosphere. If Earth's magnetic field keeps decreasing like this, the auroral electrojet will be larger during the expansion of the auroral substorm, the auroral oval will expand more to north and south, and the auroral electrojet will develop slowly.

\section{Introduction}

Earth's global magnetic field appeared approximately 3.2 billion years ago (Tarduno et al., 2007). The dipole moment of Earth's magnetic field $M$ has decreased by 9\% over the past 150 years (Olson \& Amit, 2006). The substantial decrease in the dipole magnetic moment is suggested to have a significant impact on nearEarth space environment. The ionospheric conductance has been thought to increase with decreasing with $M$ (Cnossen et al., 2011, 2012; Glassmeier et al., 2004; Takeda, 1996, 2013; Tao et al., 2017). For example, the Pedersen conductivity above $75 \mathrm{~km}$ altitude (where electron cyclotron frequency is much larger than collision frequency) is given by (Kelley, 2009, p. 45)

$$
\sigma_{P}=\frac{n e^{2}}{m_{i} v_{\text {in }}\left(1+\kappa_{i}^{2}\right)},
$$


where $n, e, m_{i}, \nu_{\text {in }}$, and $\kappa_{i}$ are the electron density, the elementary charge, the ion mass, the ion-neutral collision frequency, and the ratio of cyclotron frequency to collision frequency, respectively. Assuming that the electron density and the ion composition are independent of $M$, we can find that $\sigma_{P}$ increases with decreasing magnetic field strength. Glassmeier et al. (2004) suggested the scaling relations for the height-integrated Pedersen and Hall conductivities to be $\Sigma_{\mathrm{P}} \propto M^{-1}$ and $\Sigma_{\mathrm{H}} \propto M^{-4 / 3}$. Tao et al. (2017) performed the Groundto-topside model of Atmosphere and Ionosphere for Aeronomy with various dipole moments and found that the reduced dipole moment results in modifications of the thermospheric dynamo field $\left(\propto M^{1}\right)$, the ionospheric current $\left(\propto M^{-1}\right)$, and the ionospheric conductivities $\left(\propto M^{-3}\right.$ to $\left.M^{-2}\right)$. The simulation study with the Coupled Magnetosphere-Ionosphere-Thermosphere model shows that the amplitude of the $S_{\mathrm{q}}$ current decreases with increasing $M$ (Cnossen et al., 2011). Interestingly, the Joule heating power, the global mean thermospheric temperature, and the global mean height of the peak of the ionospheric $F_{2}$ layer do not show a monotonic increase or decrease with $M$.

The decrease in $M$ is also thought to have an impact on the magnetospheric structure. One such impact is the reduction of the stand-off distance of the magnetopause with decreasing $M$ (Cnossen et al., 2012; Siscoe \& Chen, 1975). The global magnetohydrodynamics (MHD) simulation predicts that the shape of the magnetopause is also changed when $M$ is less than $4 \times 10^{22} \mathrm{~A} \mathrm{~m}^{2}$ (Cnossen et al., 2012). Glassmeier et al. (2004) considered the extension of the magnetopause reconnection and suggested that the polar cap potential is proportional to the magnetopause stand-off distance. Assuming that the stand-off distance is proportional to $M^{1 / 3}$, they proposed that the polar cap potential is proportional to $M^{1 / 3}$. Cnossen et al. (2012) performed the global MHD simulation and pointed out that the stand-off distance does not simply obey the scaling. Siscoe and Christopher (1975) suggested that the equatorward boundary of the auroral oval moves equatorward with decreasing $M$. They regarded the inner boundary of the convection region as the equatorward boundary of the auroral oval. The net field-aligned currents (FACs) increase with decreasing $M$ because of the increase in the ionospheric conductivity (Cnossen et al., 2012; Zieger, Vogt, Ridley, et al., 2006). Glassmeier et al. (2004) considered the scaling relations for the ionospheric conductivity and the electric field and predicted that the intensity of the auroral electrojet decreases with decreasing $M$.

There were many discussions on the influence of $M$ on quasi steady state conditions of the near-Earth space environment. As far as we know, little discussion has been made on the influence of $M$ on transient phenomena, such as a substorm. The substorm is one of the most drastic, transient disturbances taking place in near-Earth space environment. The intensification of the auroral electrojet is one of the manifestations of it (Akasofu et al., 1965; Kamide \& Akasofu, 1975). The Joule dissipation rate in the ionosphere sometimes increases to $\sim 10^{11} \mathrm{~W}$ during the expansion phase of the substorm (Ahn et al., 1983; Kamide et al., 1996; Palmroth et al., 2005; Richmond et al., 1990; Rostoker et al., 1980; Tanskanen et al., 2002; Zhou et al., 2011). The $\varepsilon$ parameter (Perreault \& Akasofu, 1978) is used to estimate the amount of energy penetrating into the magnetosphere. Observations have shown that when the $\varepsilon$ parameter exceeds $10^{11} \mathrm{~W}$, a substorm occurs (Akasofu, 1980). Originally, the $\varepsilon$ parameter was derived on the basis of the Poynting flux in the solar wind interacting with the magnetosphere (Perreault \& Akasofu, 1978). Later, the $\varepsilon$ parameter is suggested to be identical to the dynamo power from the solar wind to an open magnetosphere (Kan et al., 1980). The amount of intake energy, as well as the energy stored in the magnetosphere, is expected to depend on the scale of the magnetosphere (Gonzalez \& Mozer, 1974; Siscoe \& Cummings, 1969).

Recent global MHD simulations helps understand the pathway and the conversion of energy from the solar wind to the ionosphere (Ebihara \& Tanaka, 2017; Ebihara et al., 2019). According the global MHD simulation, the magnetic energy penetrating into the magnetosphere comes from two sources: magnetic energy of interplanetary magnetic field (IMF) and solar wind kinetic energy. About 33\%-88\% of the magnetic energy passing through the magnetopause is converted from the solar wind kinetic energy near the magnetopause (Ebihara et al., 2019). In the magnetosphere, the large-scale, earthward transfer of the magnetic energy is associated with the FACs. When IMF is southward, dynamo that is responsible for the generation of the large-scale FACs appears in the mantle region (Tanaka et al., 2010). Just before the substorm expansion, additional dynamo appears in the near-Earth region. The near-Earth dynamo is closely associated with the substorm-associated FACs. Snapshots of the FACs obtained by Active Magnetosphere and Planetary Electrodynamics Response Experiment clearly demonstrate the enhancement of the FACs during the substorm expansion (Murphy et al., 2013). The substorm-associated FACs are thought to be responsible for the additional transport of the magnetic energy to the Earth during the expansion phase. 
Table 1

Simulation Settings for the Five Runs

\begin{tabular}{lcl}
\hline Name of run & $\begin{array}{c}\text { Dipole magnetic moment } M \\
\left(10^{22} \mathrm{~A} \mathrm{~m}^{2}\right)\end{array}$ & \multicolumn{1}{c}{$\begin{array}{c}\text { Ionospheric } \\
\text { conductivity }\end{array}$} \\
\hline Run 1 & 7.76 (standard run) & Standard \\
Run 2 & 11.64 & $\Sigma_{\mathrm{P}} \propto M^{-1}$ and $\Sigma_{\mathrm{H}} \propto M^{-4 / 3}$ \\
Run 3 & 5.17 & $\Sigma_{\mathrm{P}} \propto M^{-1}$ and $\Sigma_{\mathrm{H}} \propto M^{4 / 3}$ \\
Run 4 & 11.64 & Standard \\
Run 5 & 5.17 & Standard \\
\hline
\end{tabular}

The purpose of this study is to illuminate the possible influence of $M$ on the auroral substorm on the basis of the results obtained by the global MHD simulation. We arbitrarily changed $M$ in the simulation. The quadrupole component is excluded. We admit that the simulation results are somewhat speculative, but we believe that the results are useful to predict possible near-Earth space environment and to understand the solar wind-magnetosphere-ionosphere coupling that happens on Earth today as well as on other magnetized planets.

\section{Simulation}

We used the global MHD simulation developed by Tanaka (2015). This simulation consists of the solar wind-magnetosphere domain and the ionosphere domain, and they couple with each other. The solar wind-magnetosphere domain ranges from the geocentric distance of $2.6 \mathrm{R}_{\mathrm{E}}$ to $200 \mathrm{R}_{\mathrm{E}}$ at midnight and $600 \mathrm{R}_{\mathrm{E}}$ at noon. The ionosphere domain covers the ionosphere from pole to pole. The ionospheric conductivity is calculated on the basis of the FAC, the plasma pressure, and the temperature at the inner boundary of the solar wind-magnetosphere domain. The ionospheric conductivity increased by the plasma pressure and temperature is regarded as the diffuse aurora, while the conductivity increased by the (upward) FAC is regarded as the discrete aurora. We mapped the FAC from the inner boundary of the magnetospheric domain to the ionospheric domain. To satisfy the requirement of the current continuity, we solved an elliptic partial differential equation with a thin shell approximation and obtained the electric potential. The electric field is mapped from the ionosphere domain to the magnetosphere domain and is used to impose the boundary condition of the magnetosphere domain. The derivation of the ionospheric conductivity is given by Ebihara et al. (2014).

For the purpose of obtaining a quasi-steady condition, we imposed the steady solar wind condition with a speed of $400 \mathrm{~km} / \mathrm{s}$, a density of $5 \mathrm{~cm}^{-3}$, IMF $B_{\mathrm{y}}$ of 0 , and IMF $B_{\mathrm{z}}$ of $3 \mathrm{nT}$ for $2 \mathrm{~h}$. Then, we turned IMF $B_{\mathrm{z}}$ from $3 \mathrm{nT}$ to $-5 \mathrm{nT}$ at $t=120 \mathrm{~min}$ as a step function in the upstream solar wind. The dipole moment of the Earth $M$ was set to be $7.76 \times 10^{22} \mathrm{~A} \mathrm{~m}^{2}$, which corresponds to the present Earth. This is a standard run, which is hereinafter referred to as Run 1. In Run 2, we increased $M$ by $50 \%$, that is, $11.64 \times 10^{22} \mathrm{~A} \mathrm{~m}^{2}$, which corresponds to the Earth about 2,650 years ago (Knudsen et al., 2008). In Run 3, we decreased $M$ by $50 \%$, that is, $5.17 \times 10^{22} \mathrm{~A} \mathrm{~m}^{2}$. If the rate of change in $M$ remains constant in future, this $M$-value will correspond to the Earth in about 2850 AD. In Runs 2 and 3, we multiplied the height-integrated Pedersen and Hall conductivities with the aid of the scaling relations, $\Sigma_{\mathrm{P}} \propto M^{-1}$ and $\Sigma_{\mathrm{H}} \propto M^{-4 / 3}$, suggested by Glassmeier et al. (2004). Runs 4 and 5 are the same as Runs 2 and 3, respectively, except that the ionospheric conductivities were not multiplied in accordance with $M$. This means that we calculated the ionospheric conductivities in Runs 4 and 5 in the same manner as Run 1 . Runs 4 and 5 are probably unrealistic because the ionospheric conductivity is independent of $M$ but are used to isolate the contribution from the ionospheric conductivity. The simulation settings are summarized in Table 1.

\section{Results}

Figure 1 shows the calculated auroral electrojet indices, SMU and SML. The SMU/SML indices are extension of the AU/AL indices to overcome the ambiguities arising from the limited number of observatories (Newell \& Gjerloev, 2011a). We calculated the magnetic disturbances induced by the ionospheric Hall current at magnetic latitudes (MLAT) from $50^{\circ}$ to $90^{\circ}$ with an interval of $1^{\circ}$ in MLAT and $0.5 \mathrm{~h}$ in the magnetic local time. The auroral electrojet is known to be closely associated with the auroral activities (Akasofu et al., 1965; Kamide \& Akasofu, 1975; Obayashi \& Nishida, 1968). Originally, an abrupt intensification of the auroral brightness is used to identify the onset of expansion phase of substorms (Akasofu, 1964). Here, we use the sudden enhancement of the auroral electrojets to identify substorms onset (Akasofu et al., 1965; Newell \& Gjerloev, 2011a, 2011b; Rostoker et al., 1980). Following Newell and Gjerloev (2011a), we determined the expansion onset $t_{0}$ when all the following criteria are satisfied.

$$
\operatorname{SML}\left(t_{0}+1 \min \right)-\operatorname{SML}\left(t_{0}\right)<-15 \mathrm{nT}
$$


(a)

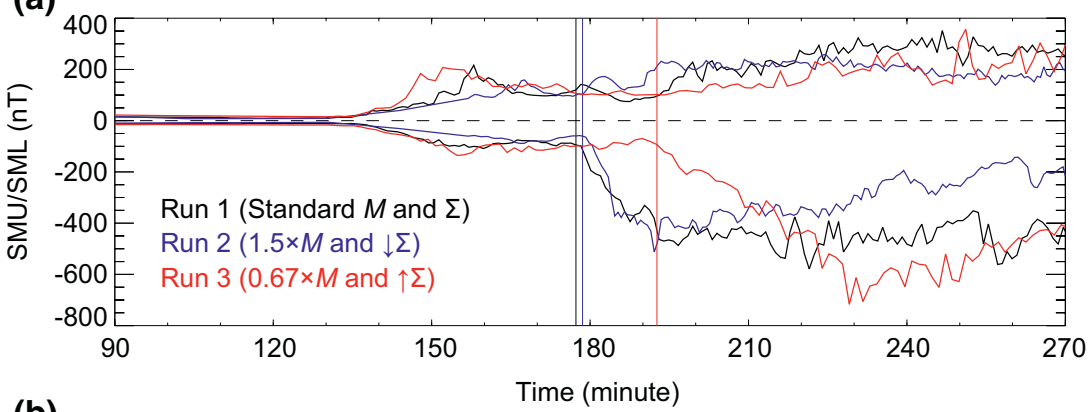

(b)

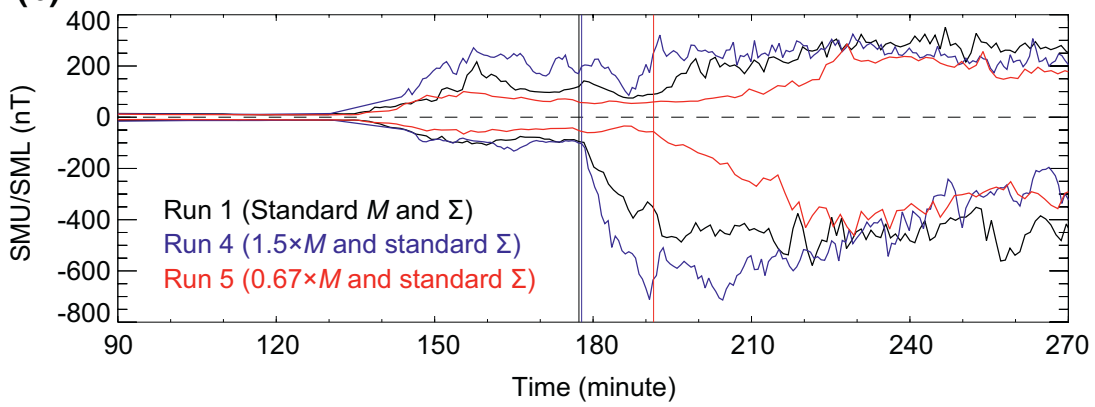

Figure 1. Calculated SMU and SML indices. The vertical lines indicate the time of expansion onset.

$$
\begin{gathered}
S M L\left(t_{0}+2 \mathrm{~min}\right)-S M L\left(t_{0}\right)<-30 \mathrm{nT} \\
S M L\left(t_{0}+3 \min \right)-S M L\left(t_{0}\right)<-45 \mathrm{nT} \\
\frac{1}{26} \sum_{i=4}^{30} S M L\left(t_{0}+i \min \right)-S M L\left(t_{0}\right)<-100 \mathrm{nT}
\end{gathered}
$$

Table 2

Minimum SML Within 60 min From the Expansion Onset, Cross-Polar Cap Potential Drop at the Expansion Onset, Maximum Speed of Sunward Flow in Near-Earth Plasma Sheet at Onset, Rate of Magnetic Energy

\begin{tabular}{|c|c|c|c|c|c|}
\hline $\begin{array}{l}\text { Name } \\
\text { of } \\
\text { run }\end{array}$ & $\begin{array}{l}\text { Minimum } \\
\text { SML (nT) }\end{array}$ & $\begin{array}{l}\text { Cross- } \\
\text { polar } \\
\text { cap } \\
\text { potential } \\
\text { at onset } \\
(\mathrm{kV})\end{array}$ & $\begin{array}{c}\text { Maximum } \\
\text { speed of } \\
\text { sunward } \\
\text { flow in } \\
\text { plasma } \\
\text { sheet at } \\
\text { onset } \\
(\mathrm{km} / \mathrm{s})\end{array}$ & $\begin{array}{l}\text { Near- } \\
\text { Earth } \\
\text { dynamo } \\
\text { at onset } \\
\left(10^{10} \mathrm{~W}\right)\end{array}$ & $\begin{array}{c}\text { Incident } \\
\text { magnetic } \\
\text { energy into } \\
\text { magnetosphere } \\
\text { at onset } \\
\left(10^{10} \mathrm{~W}\right)\end{array}$ \\
\hline Run 1 & -579 & 75 & 406 & 5.7 & 118 \\
\hline Run 2 & -513 & 86 & 772 & 7.1 & 137 \\
\hline Run 3 & -717 & 57 & 246 & 3.9 & 96 \\
\hline Run 4 & -714 & 83 & 891 & 7.4 & 136 \\
\hline Run 5 & -462 & 72 & 267 & 3.5 & 96 \\
\hline
\end{tabular}
Generated in Near-Earth Region (Near-Earth Dynamo) at Onset, and Incident Magnetic Energy Into the Magnetosphere at Onset

The expansion onset determined by the above criteria is displayed by the vertical lines in Figure 1. The minimum values of SML within 60 min from the expansion onset are summarized in Table 2.

The black lines in Figure 1 show the SMU and SML indices for Run 1 (which corresponds to the present Earth). The lower line indicates SML, which starts to decrease gradually at $t \sim 136$ min and stays almost constant until $t \sim 177 \mathrm{~min}$. This period corresponds to the growth phase of the substorm (McPherron, 1970). SML shows a sudden decrease at $t \sim$ $177 \mathrm{~min}$. This moment is identified as the expansion onset, according to the above criteria (Newell \& Gjerloev, 2011a). SML reached the minimum value of $-579 \mathrm{nT}$ within 60 min from the expansion onset. For Run 2 (in which $M$ is 1.5 times larger than present and the ionospheric conductivity decreases), SML recovers earlier than for Run 1 . The minimum value of SML is -513 nT. For Run 3 (in which $M$ is 1.5 times smaller than present and the ionospheric conductivity increases), SML decreases slowly in comparison with those for Runs 1 and 2. The minimum value of SML is $-717 \mathrm{nT}$, which is smaller than that for Runs 1 and 2. The result indicates that the maximum intensity of the westward electrojet increases with decreasing $M$. When the ionospheric conductivity is independent of $M$, the situation is different (as shown in the bottom panel of Figure 1). SML reached the minimum value of $-714 \mathrm{nT}$ for 

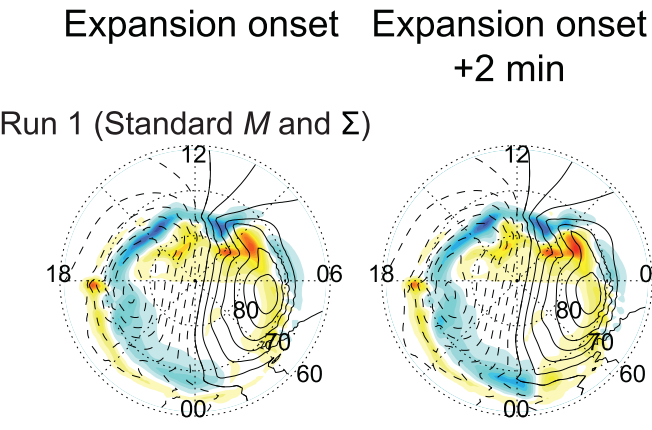

Run $2(1.5 \times M$ and $\downarrow \Sigma)$

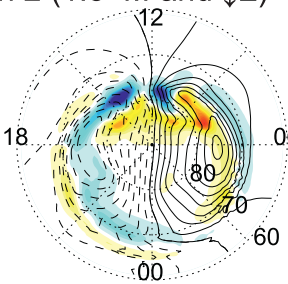

Run $3(0.67 \times M$ and $\uparrow \Sigma)$
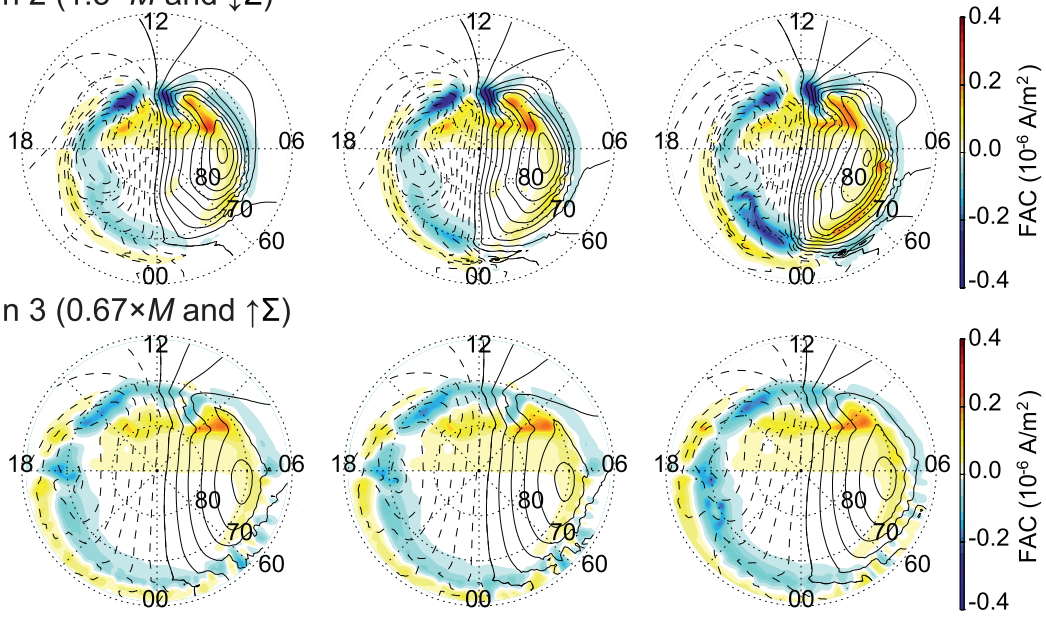

Run $4(1.5 \times M$ and standard $\Sigma)$

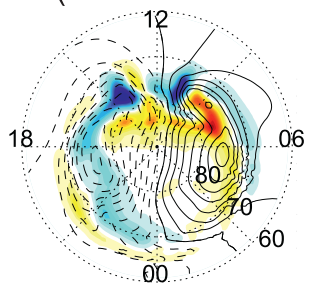

618
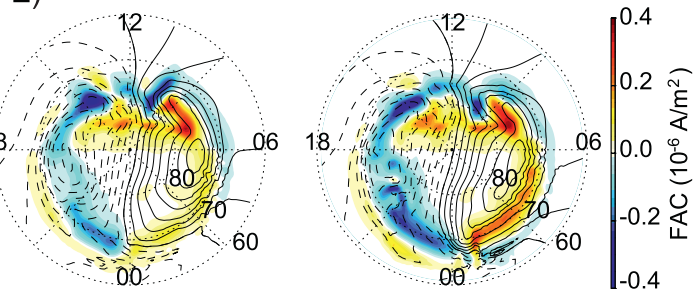

Run $5(0.67 \times M$ and standard $\Sigma)$
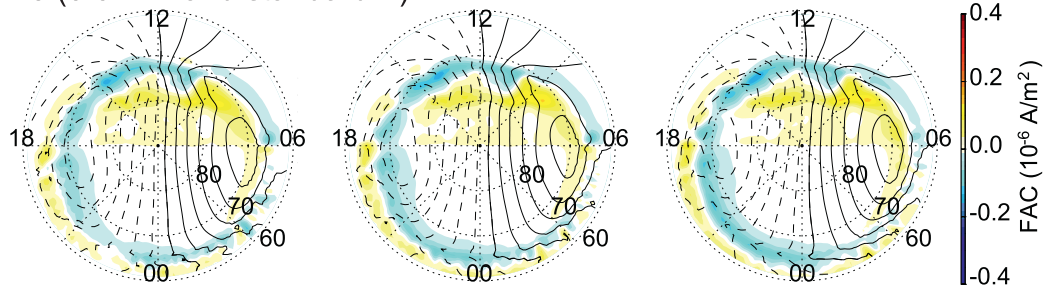

Figure 2. Field-aligned currents at the ionosphere altitude (left) at the expansion onset, (middle) 2 min after the onset, and (right) $5 \mathrm{~min}$ after the onset. Positive downward (red) and negative upward (blue). The Sun is to the top. The contour lines indicate the ionospheric electric potential at an interval of $5 \mathrm{kV}$. The solid lines mean the positive potential, whereas the dashed ones mean the negative potential.

Run 4, whereas it reached the minimum value of $-462 \mathrm{nT}$ for Run 5. Namely, the maximum intensity of the westward electrojet increases when we increase the ionospheric conductivity.

Figure 2 summarizes the FACs for the first 5 min from the expansion onset. At a glance, the global distributions of FACs resemble the Region 1 and Region 2 FACs (Iijima \& Potemra, 1976) for all the runs. Both the Region 1 and Region 2 FACs are intensified after the expansion onset, in particular, on nightside. This tendency is consistent with observations (Coxon et al., 2014). For Runs 1 and 2, a surge-like structure of the upward FACs appears in the postmidnight sector immediately after the expansion onset. In the simulation, 
(a)

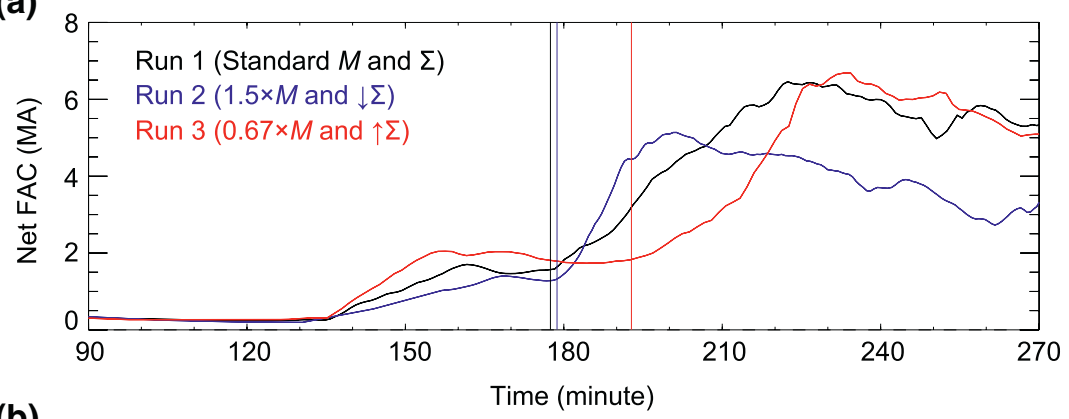

(b)

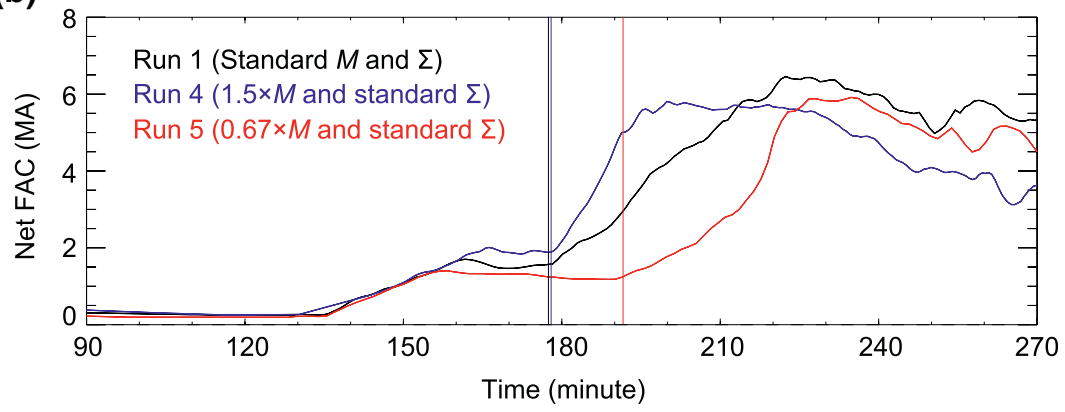

Figure 3. Net field-aligned current flowing into and out of the ionosphere in both the hemispheres. The vertical lines indicate the time of expansion onset.

the surge-like structure traveling westward is caused by the mutual interaction between the magnetosphere and the ionosphere (Ebihara \& Tanaka, 2015a, 2018). For Run 3, the surge-like structure appears later (not shown). The FAC distribution for Run 4 is similar to that for Run 2, whereas the intensity of the FACs for Run 4 is somewhat larger than for Run 2. The FAC distribution for Run 5 is also similar to that for Run 3. The intensity of the FACs for Run 5 is smaller than for Run 3. There is a tendency that the intensity of the substorm-associated FACs increases with increasing $M$.

The contour lines overlaid on the FACs in Figure 2 represent the electric potential. The two-cell convection pattern is confined at high latitudes for the large $M$-value as Siscoe and Christopher (1975) pointed out. The cross-polar cap potential (CPCP) drop in the Northern Hemisphere at the expansion onset (the end of the growth phase) is summarized in Table 2. A clear tendency can be identified that the CPCP increases with increasing $M$. This is consistent with a theoretical study (Siscoe \& Chen, 1975) and simulation studies (Cnossen et al., 2012; Zieger, Vogt, \& Glassmeier, 2006).

Table 3

Maximum Value of the Net FAC, Joule Heating Rate in the Ionosphere, Rate of Magnetic Energy Generated in Near-Earth Region (Near-Earth Dynamo), and Incident Magnetic Energy Into the Magnetosphere at the Moment When the Net FAC Reaches Maximum

\begin{tabular}{lcccc}
\hline Name & $\begin{array}{c}\text { Net } \\
\text { FAC } \\
\text { of }\end{array}$ & $\begin{array}{c}\text { Joule heating rate } \\
\text { in the ionosphere } \\
\left(10^{10} \mathrm{~W}\right)\end{array}$ & $\begin{array}{c}\text { Near-Earth } \\
\text { dynamo } \\
\left(10^{10} \mathrm{~W}\right)\end{array}$ & $\begin{array}{c}\text { Incident magnetic } \\
\text { energy into } \\
\text { magnetosphere } \\
\left(10^{10} \mathrm{~W}\right)\end{array}$ \\
\hline Run 1 & 6.5 & 3.0 & 48 & 132 \\
Run 2 & 5.1 & 3.4 & 50 & 176 \\
Run 3 & 6.7 & 3.3 & 24 & 109 \\
Run 4 & 5.8 & 3.3 & 48 & 194 \\
Run 5 & 5.9 & 3.2 & 22 & 97 \\
\hline
\end{tabular}

Figure 3 shows the net FAC flowing into and out of the ionosphere in both the hemispheres. For Runs 1-3, the net FAC increases with decreasing $M$ during the growth phase. This is consistent with the simulation study (Cnossen et al., 2012). During the expansion phase, the net FAC increases faster and starts to recover earlier for larger $M$-value. The maximum value of the net FAC decreases with increasing $M$. When the ionospheric conductivity is independent of $M$ (Runs 1, 4, and 5), the net FAC increases with increasing $M$ during the growth phase. This tendency is different from the cases that the ionospheric conductivity depends on $M$ (Runs 1-3). During the expansion phase, the maximum values of the net FAC are almost independent of $M$. (They are summarized in Table 3.) These results imply that higher conductivity gives rise to higher net FACs and that the contribution from the ionospheric conductivity significantly regulates the net FACs.

Figure 4 summarizes the FAC, the nondiagonal component of the ionospheric conductivity (Hall conductivity), the intensity of the ionospheric 

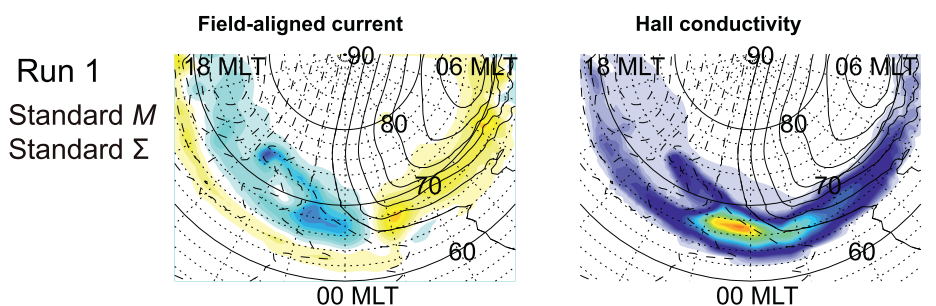

$00 \mathrm{MLT}$

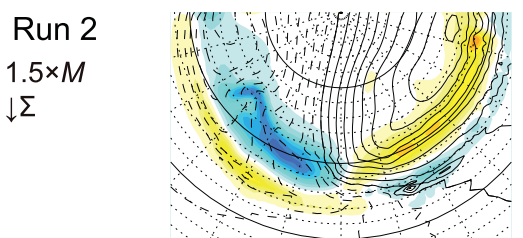

Run 3

$0.67 \times M$

$\uparrow \Sigma$
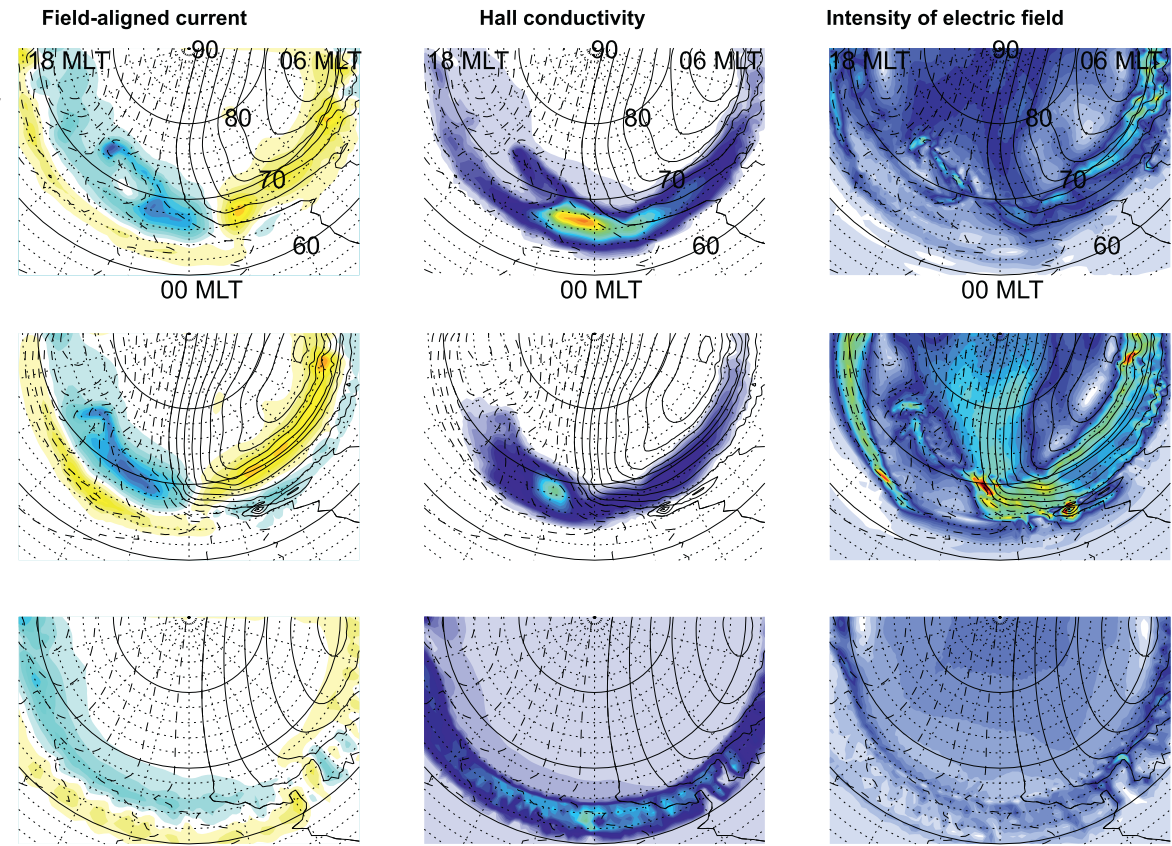

$00 \mathrm{MLT}$
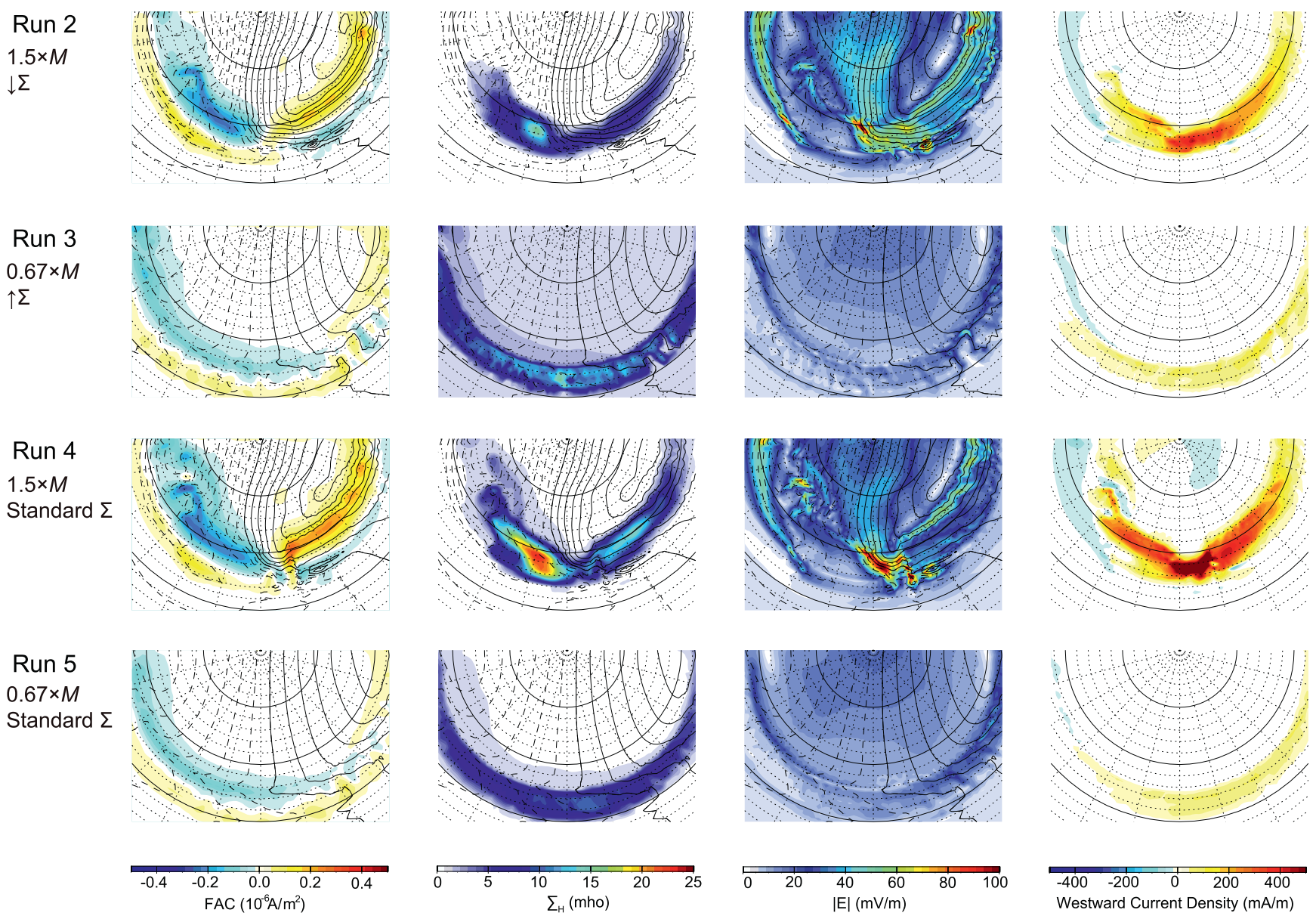

Figure 4. From left to right, field-aligned current (negative upward), nondiagonal component of the ionospheric conductivity (Hall conductivity), intensity of the ionospheric electric field, and azimuthal component of the ionospheric current (positive westward) at 5 min after the expansion onset. The Sun is to the top.

electric field, and the azimuthal component of the ionospheric current at $5 \mathrm{~min}$ after the expansion onset. By looking at the results for Runs 1 and 4, one can find that all the quantities (the FAC, the ionospheric conductivity, the ionospheric electric field, and the ionospheric current) increase with increasing $M$. The large increase in the ionospheric current results in the rapid development of the auroral electrojet as shown in Figure 1. When we introduce the ionospheric conductivity model depending on $M\left(\Sigma_{\mathrm{P}} \propto M^{-1}\right.$ and $\Sigma_{\mathrm{H}} \propto M^{-4 / 3}$ ), the auroral electrojet decreases with increasing $M$ (from Run 4 to Run 2). One simple explanation for the decrease in the auroral electrojet is the decreases in the conductivity and the electric field. (From Run 4 to Run 2, the electric field increases in the polar cap, but it does not directly affect the intensity of the auroral electrojet.) Another explanation, which is probably more essential, is that the auroral electrojet is largely regulated by the FAC. To satisfy the current continuity, when the FAC decreases, the ionospheric current must decrease. However, the situation is not so simple because the FAC, the ionospheric conductivity, the ionospheric electric field, and the ionospheric current are coupled with each other. So far, the reason why the FAC depends on the ionospheric conductivity is still unknown. This is an important subject to be investigated in the future. 


\section{Run 1 \\ Standard $M$ Standard $\Sigma$}

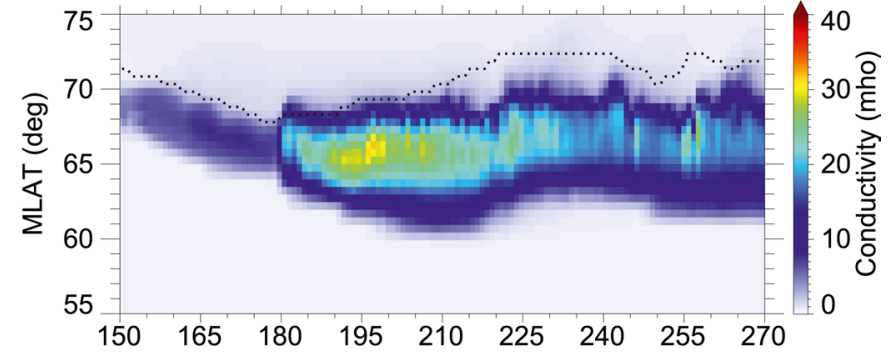

Run 2

$1.5 \times M$

$\downarrow \Sigma$

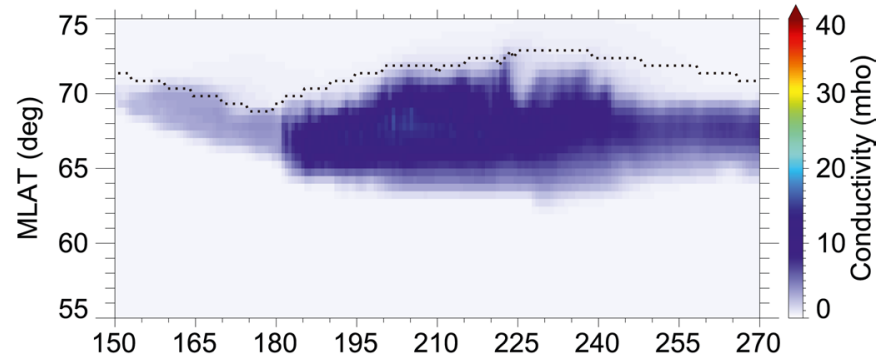

\section{Run 3 \\ $0.67 \times M$ \\ $\uparrow \Sigma$}

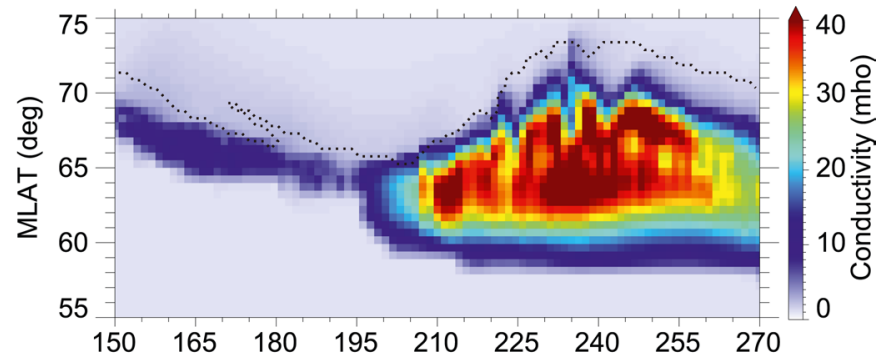

Run 4
$1.5 \times M$
Standard $\Sigma$

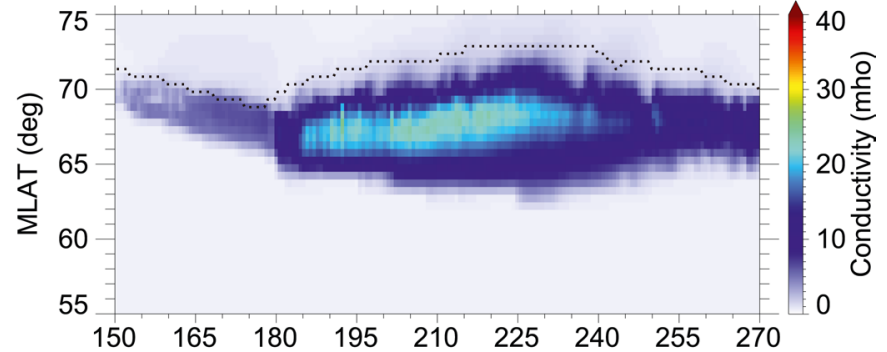

Run 5

$0.67 \times M$

Standard $\Sigma$

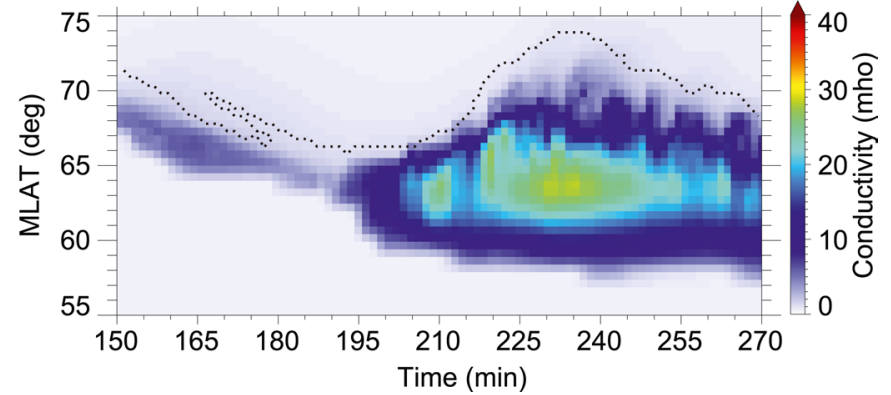

Figure 5. Nondiagonal component of the ionospheric conductivity (which can be regarded as a proxy of auroral brightness) at midnight as a function of magnetic latitude (MLAT) and time. The dashed line indicates the open-closed boundary of the magnetic field line.

Figure 5 shows the nondiagonal component of the ionospheric conductivity (the Hall conductivity) as a function of MLAT and time at magnetic midnight. Hereinafter, we regard the ionospheric conductivity as aurora for the sake of simplicity. The observations show that the auroral brightness is correlated with the ionospheric conductivity (Kamide et al., 1986; Robinson et al., 1989). Noticeable points can be summarized below. During the growth phase, the poleward boundary of the auroral oval and the open-closed boundary 


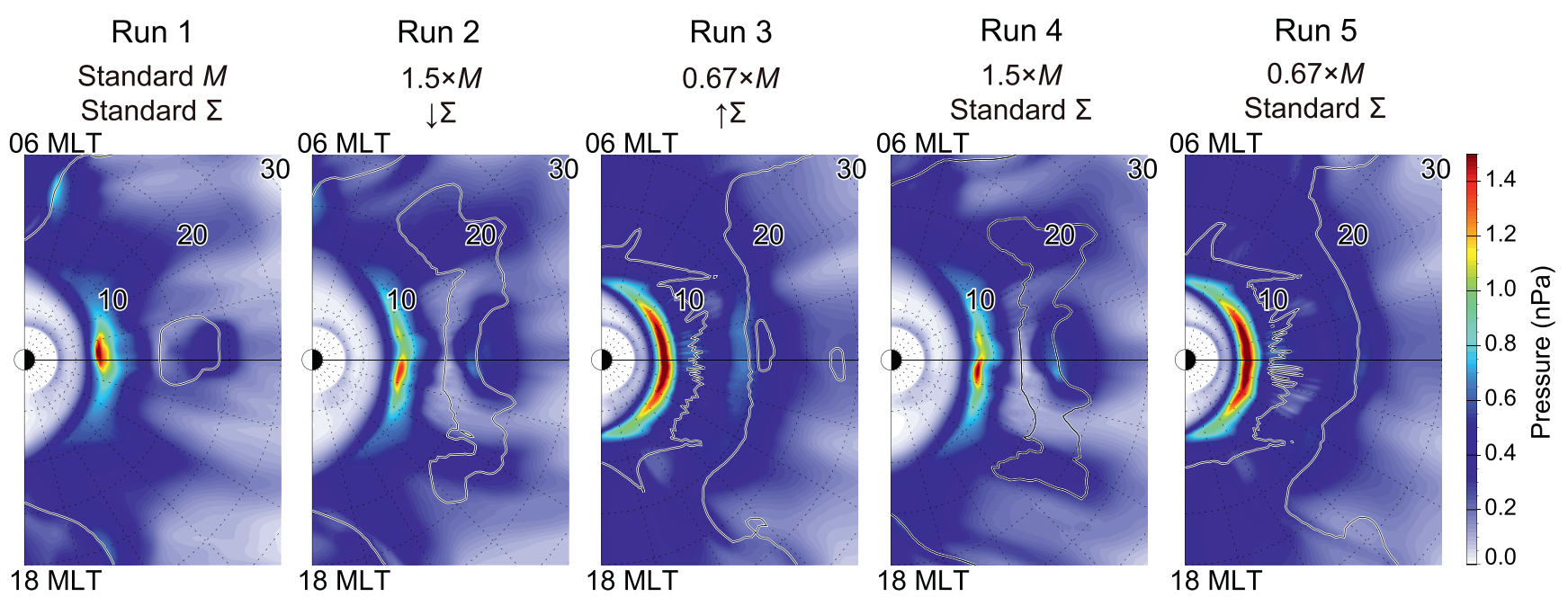

Figure 6. Plasma pressure in the equatorial plane. The black contour indicates that the $Z$-component of the magnetic field is zero. The Sun is to the left.

move equatorward. Just before the expansion onset, the open-closed boundaries are located at $\sim 68, \sim 69$, $\sim 66, \sim 68$, and $\sim 66$ MLAT for Runs 1, 2, 3, 4, and 5, respectively. This means that the open-closed boundary shifts poleward with increasing $M$. The dependence of the open-closed boundary on $M$ is consistent with the previous simulation study (Cnossen et al., 2012). The equatorward boundary of the auroral oval also moves equatorward during the growth phase. Just before the expansion onset, the boundaries are located at $\sim 64, \sim 66, \sim 63, \sim 66$, and $\sim 63$ MLAT for Runs 1, 2, 3, 4, and 5, respectively. The equatorward boundary shifts poleward by $\sim 2^{\circ}$ when $M$ is increased by 1.5 , and shifts equatorward by $\sim 1^{\circ}$ when $M$ is decreased by a factor of 1.5. During the expansion phase, the auroral oval expands less poleward and equatorward for stronger $M$. The poleward boundary of the auroral oval does not always coincide with the polar cap boundary during substorm expansion (Birn \& Hesse, 2013; Ebihara \& Tanaka, 2015a, 2017).

Figure 6 shows the plasma pressure in the equatorial plane at the expansion onset. By the expansion onset, the plasma pressure has been well developed on the nightside as previously pointed out on the basis of observations (Yao et al., 2015a, 2015b) and simulations (Ebihara \& Tanaka, 2015b; Tanaka et al., 2010, 2017). The enhancement of the plasma pressure is associated with compression that happens when the earthward flowing plasma is decelerated (Birn \& Hesse, 2005; Tanaka et al., 2010, 2017). The deceleration is primarily caused by the pressure force directing outward. The peak of the plasma pressure takes place at $X \cong-7 \mathrm{R}_{\mathrm{E}}$ (Run 1), $-8 \mathrm{R}_{\mathrm{E}}$ (Runs 2 and 4), and $-6 \mathrm{R}_{\mathrm{E}}$ (Runs 3 and 5). The result indicates that the peak of the plasma pressure takes place at greater distance for larger $M$ because the outward pressure force increases with increasing $M$. The force balance is highly variable near the substorm expansion onset as suggested by Ebihara and Tanaka (2013) but is not shown here. The earthward flow results from the formation of a near-Earth neutral line, which can be identified from the earthward part of the black contour indicating that the $Z$-component of the magnetic field is zero. They are located at $X \cong-13 \mathrm{R}_{\mathrm{E}}$ (Runs 1,2 , and 4), and $\cong-9 \mathrm{R}_{\mathrm{E}}$ (Runs 3 and 5). The near-Earth neutral line forms at greater distance for larger $M$, but the reason is not known.

In the ionosphere, the Joule dissipation rate increases significantly in a latitudinally confined region during the substorm expansion (Ahn et al., 1983; Kamide et al., 1996; Lu et al., 2016). To supply the magnetic energy into such confined region, the energy transfer should be associated with FACs, and the magnetic energy must be generated somewhere in the field line connecting to the auroral region. The global MHD simulation results show that the near-Earth dynamo is the one that is responsible to supply the magnetic energy into the auroral region during the substorm expansion (Birn \& Hesse, 2005; Ebihara \& Tanaka, 2015a, 2015b; Tanaka, 2015). Figure 7 summarizes perspective views of the magnetosphere at the expansion onset. The light and dark greenish surfaces indicate the regions where $\mathbf{J} \cdot \mathbf{E}=-2 \times 10^{-12}$ and $-4 \times 10^{-12} \mathrm{~W}$ $\mathrm{m}^{-3}$, respectively. This region is called a near-Earth dynamo and is responsible for the generation of the substorm-associated FACs. To evaluate the near-Earth dynamo, we calculated the volume integral of $\mathbf{J} \cdot \mathbf{E}$ for the region where $\mathbf{J} \cdot \mathbf{E}<0$ in the rectangular region ranging from $X=-15 R_{E}$ to $0, Y=-10_{E}$ to $10 R_{E}$, 


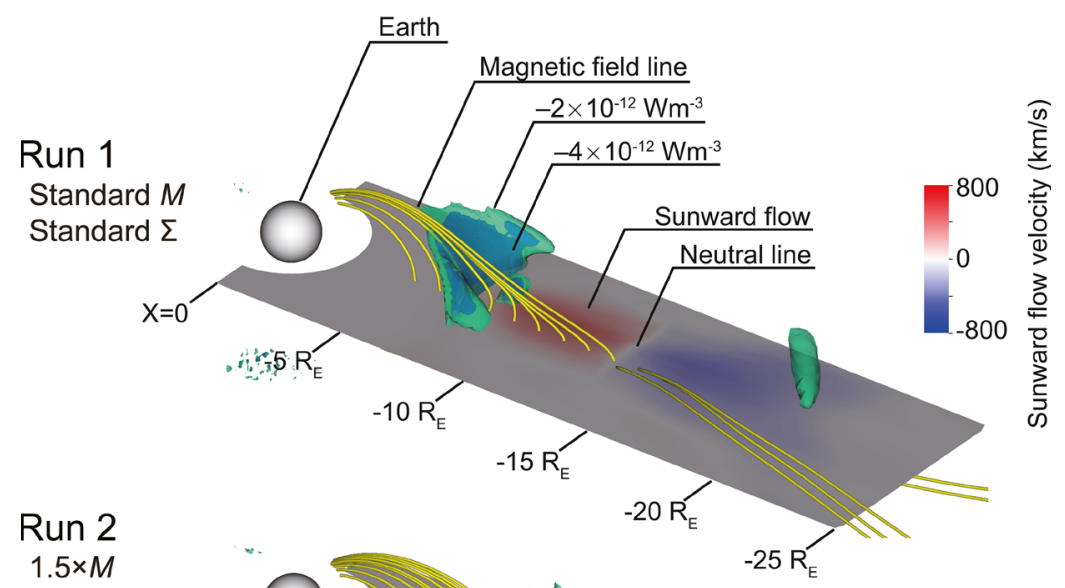

$\downarrow \Sigma$

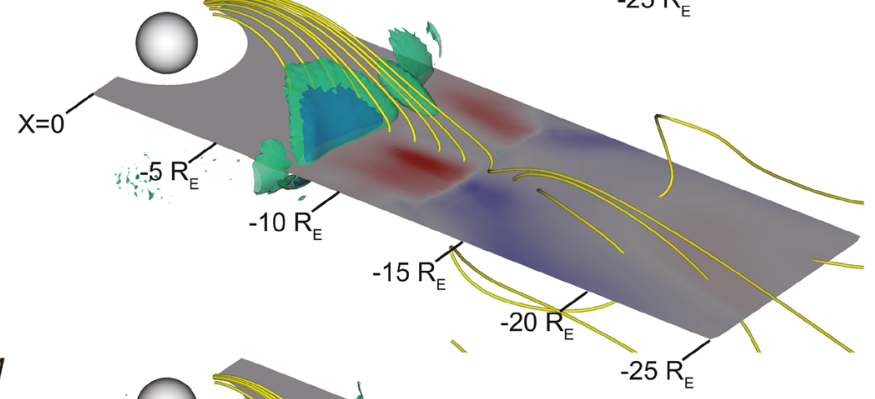

Run 3

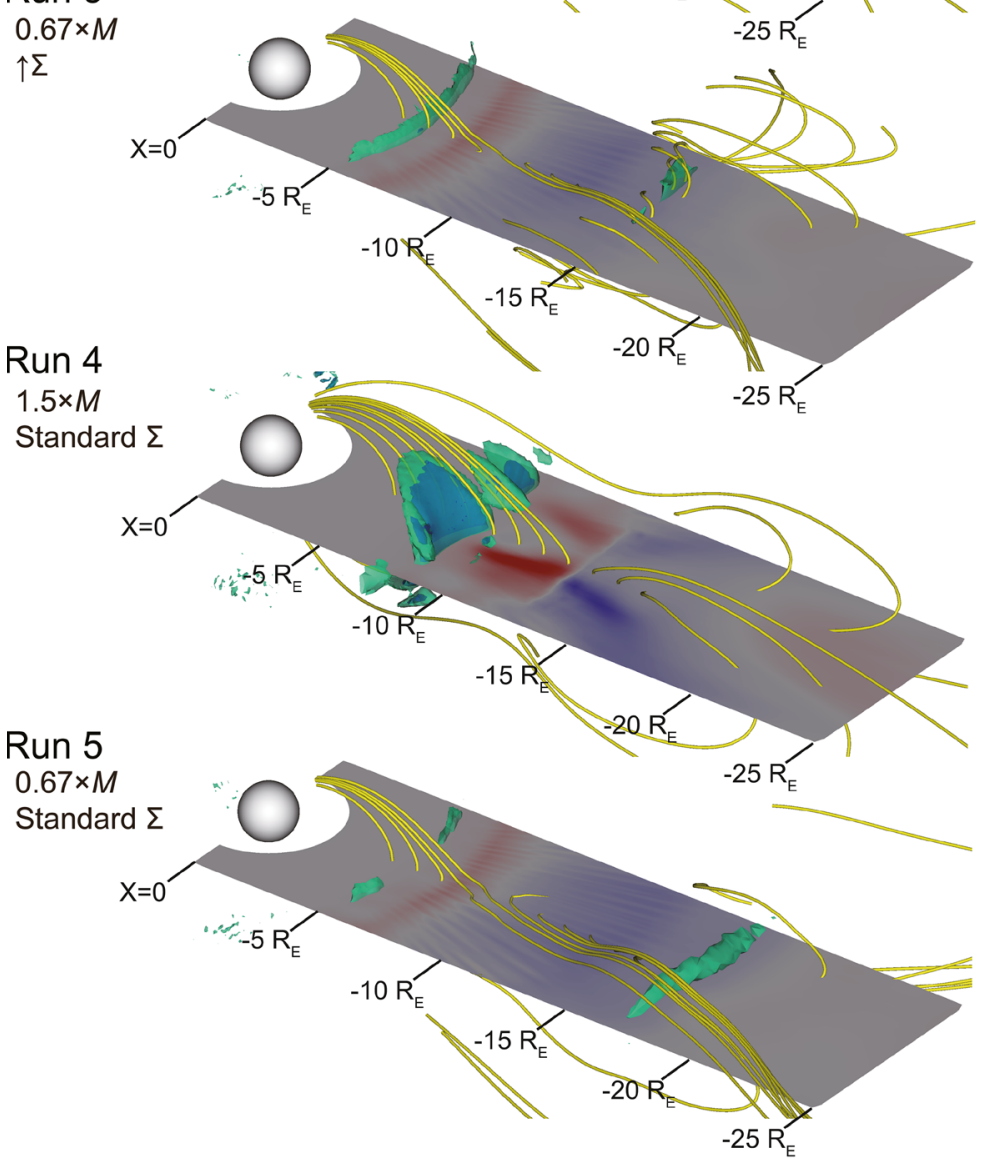

Figure 7. Perspective view of the magnetosphere as if one is looking down the Earth from the dusk-midnight sector above the equatorial plane. All the views were obtained at the expansion onset. The yellow lines indicate the magnetic field lines. The light and dark greenish surfaces indicate the $\mathbf{J} \cdot \mathbf{E}$ values of $-2 \times 10^{-12}$ and $-4 \times 10^{-12} \mathrm{~W}$ $\mathrm{m}^{-3}$, respectively. The sunward flow velocity is indicated by color in the equatorial plane (at $Z=0$ ). The white sphere indicates the Earth. 
and $Z=-5 R_{E}$ to $5 R_{E}$. The results are summarized in Table 2 . The generation rate of the magnetic energy increases with increasing $M$. This gives rise to the rapid development of the net FAC and the auroral electrojet for larger $M$-values. The sunward flow of plasma is indicated by the red color in the equatorial plane. The maximum speed of the sunward flow increases with increasing $M$ as summarized in Table 2. For larger $M$-values, the relatively high-speed flow can enhance the plasma pressure (thermal energy) more efficiently because $\partial P / \partial t=-\mathbf{V} \cdot \nabla P-\gamma P \nabla \cdot \mathbf{V}$, where $P, \mathbf{V}$, and $\gamma$ are the plasma pressure, the bulk velocity, and the ratio of specific heat $(=5 / 3)$, respectively (Birn \& Hesse, 2005).

We calculated the incident magnetic energy into the magnetosphere by integrating the Poynting flux over the surface of the magnetosphere at the expansion onset. The methodology for the calculation is described by Ebihara et al. (2019) in detail. The results are summarized in Table 2. The incident magnetic energy increases with increasing $M$ probably due to the inflation of the magnetosphere for larger $M$-value. Table 3 summarizes the net FAC, the Joule heating rate in the ionosphere, the generation rate of magnetic energy in the near-Earth dynamo, and the incident magnetic energy into the magnetosphere at the moment when the net FAC reaches maximum. A noticeable feature is that the maximum value of the net FAC decreases with increasing $M$, whereas the incident magnetic energy into the magnetosphere increases with increasing $M$. This implies that the efficiency of the generation of the substorm-associated FAC increases with decreasing $M$. The ratios of the Joule heating rate in the ionosphere to the incident magnetic energy into the magnetosphere are $2.3 \%, 1.9 \%$, and $3.0 \%$ for Runs 1, 2, and 3, respectively, meaning that the ratio increases with decreasing $M$. For lower $M$-values, the incident energy into the magnetosphere is efficiently transported to the ionosphere.

\section{Discussion}

It will take $\sim 830$ years to decrease $M$ by $50 \%$ if the rate of the change in $M$ is constant. Thus, the results presented above cannot be verified by observations until the very distant future. We repeated the same simulation except that $M$ increases by $\sim 3 \%$ (Run $2^{\prime}$ ) and $M$ decreases by $\sim 3 \%$ (Run $3^{\prime}$ ). The $6 \%$ decrease in $M$ corresponds to the recent change in Earth's $M$ over $\sim 100$ years. The calculated SMU/SML index is shown in Figure S1. The difference is very small. One cannot easily identify the contribution from the secular variation of $M$ to the SMU/SML index on the basis of data acquired over 100 years. For this reason, we have considered larger changes in $M$ to more clearly understand and characterize the changes in the development of substorms in response to varying the dipole moment.

The change in $M$ has significant consequences on the development of the auroral electrojet. For the lower $M$-value, (1) the expansion onset takes place later, (2) the auroral electrojet develops slowly, and (3) the maximum auroral electrojet increases. These consequences are closely related to the FACs that develops during the expansion phase. The first two consequences are probably associated with the slow magnetospheric convection as manifested by the polar cap potential (i.e., Table 2). The relatively low speed of the sunward flow in the near-Earth plasma sheet (i.e., Table 2) may also cause the slow evolution of the auroral electrojet. In the near-Earth dynamo, the generation rate of the magnetic energy increases with increasing $M$, which may result from the relatively high speed of the sunward flow in the near-Earth plasma sheet (i.e., Table 2). The pattern of the sunward flow depends on $M$ (i.e., Figure 7), but we have no reasonable explanation for that dependency. The third consequence can be understood to the nonlinear dependence of the substorm-associated FACs on the ionospheric conductivity. The magnetosphere-ionosphere coupling processes is essentially nonlinear, and this nonlinear process is beyond the scope of this paper. We will investigate the influence of the ionospheric conductivity on the whole magnetospheric system in the future.

Regarding the third consequence, the simulation result opposes to the theoretical prediction (Glassmeier et al., 2004) that the magnitude of the auroral electrojet increases with increasing $M$. Glassmeier et al. (2004) considered that the magnitude of the auroral electrojet depends on the ionospheric conductivity and the electric field. However, our simulation result shows that the FACs also depend on $M$, and that the maximum value of the net FAC increases with decreasing $M$. The dependence of the FACs on the conductivity is also shown to be significant.

The dipole magnetic moment of $11.64 \times 10^{22} \mathrm{~A} \mathrm{~m}^{2}$, which is used for Runs 2 and 4, roughly corresponds to that about 2650 years ago, during which the highest dipole moment occurred throughout the Holocene pe- 
riod (Knudsen et al., 2008). Coincidently, the earliest records of candidate aurorae are dated back to similar age (Hayakawa, Mitsuma, et al., 2019). The Assyrian cuneiform tablets ( 679-655 BCE) described situations of "a red glow [keeps blazing] at [the zenith]," "a red cloud keeps being placed in the sky," and "red covers the sky." These statements are most likely interpreted as reddish aurorae that covered the sky over at Nineveh or Babylon at which the geomagnetic latitude was $\sim 35-41^{\circ}$. With an empirical relationship between the equatorward boundary of the auroral oval and the Dst index (Yokoyama et al., 1998), Hayakawa, Mitsuma, et al. (2019) suggested that large magnetic storms occurred during these occasions. The scale of the storms is estimated to be comparable to that occurred in 1909 (minimum Dst of -595 nT) (Hayakawa, Ebihara, et al., 2019). This empirical relationship was obtained on the basis of data acquired between 1983 and 1991 during which $M$ ranges from $7.88 \times 10^{22}$ to $7.83 \times 10^{22} \mathrm{~A} \mathrm{~m}^{2}$, according to the international geomagnetic reference field (Thébault et al., 2015). Figure 5 suggests that the equatorward boundary of the auroral oval would shift poleward by $\sim 2^{\circ}$ about 2650 years ago than present for the same solar wind condition. Stronger solar wind driver is required to generate the auroral oval that is located at the same MLAT as today. For Run 2, the equatorward boundary of the auroral oval is located at 66 MLAT just before the expansion onset. We repeated Run 2 except that we increased the solar wind speed from 400 to $500 \mathrm{~km} / \mathrm{s}$ (data not shown). The equatorward boundary is located at $~ 64$ MLAT, which approximately corresponds to that for Run 1 . This speculation would be applicable for all the estimation of the solar wind conditions based on historical records back for the last 2650 years from now because the highest dipole moment occurred at that time throughout the Holocene period (Knudsen et al., 2008). From that sense, the poleward shift of $\sim 2^{\circ}$ would be the upper limit throughout the Holocene period for the same solar wind condition.

For possible impacts on space weather, the following prediction can be drawn. If $M$ keeps decreasing in future, the maximum intensity of the auroral electrojet will increase. The increased auroral electrojet may increase geomagnetically induced currents that are hazardous to power grid (Boteler et al., 1998; Pirjola \& Viljanen, 1989). Once the substorm occurs, the auroral oval is expected to expand more poleward and equatorward. This means that the harmful area will also expand both to the poleward and equatorward. If $M$ decreases, hot electrons originating in the nightside plasma sheet will penetrate deeper during the substorm expansion as shown in Figure 7. The hot electrons result in static charge on the surface of satellite, and large discharges and arc (Garrett, 1981; Rosen, 1976). Overall, the decrease in the value of Earth's dipole moment may have a greater impact on human activities than present.

\section{Conclusions}

We performed the global MHD simulation with different dipole magnetic moment $M$. We increased and decreased $M$ by a factor of 1.5 and changed the ionospheric conductivity in accordance with $M$. When we imposed southward IMF, auroral substorms took place regardless of $M$. However, the evolution of the auroral substorm shows a dependence on $M$. The following conclusions can be drawn.

1. For the lower $M$-value, the expansion onset takes place later, the auroral electrojet develops slowly, and the maximum auroral electrojet increases. The first two consequences are probably associated with the slow magnetospheric convection as manifested by the polar cap potential. The third consequence can be understood to the nonlinear dependence of the substorm-associated FACs on the ionospheric conductivity.

2. For the lower $M$-value, the amount of incident magnetic energy into the magnetosphere decreases, whereas the maximum auroral electrojet increases. This implies that the efficiency of the generation of the substorm-associated FACs increases with decreasing $M$.

3. For the lower $M$-value, the auroral oval shifts equatorward during the growth phase and expands more equatorward and poleward during the expansion phase.

The results presented here are not definitive because we omitted the kinetic processes related to particle precipitation, we excluded the contribution from the quadrupole component, and we used simple relations between the ionospheric conductivity and $M$. Careful investigations are needed to fully understand the future substorms. 


\section{Data Availability Statement}

The simulation data used in this study are available at http://doi.org/10.5281/zenodo.4003656.

\section{Acknowledgments}

YE thanks Prof. Kazunari Shibata for inspiring the study on the influence of Earth's dipole moment on near-Earth space environment and Dr Hisashi Hayakawa for discussion about the description in Assyrian cuneiform tablets. The computer simulation was performed on the KDK computer system at the Research Institute for Sustainable Humanosphere (RISH), Kyoto University. This study was supported by JSPS KAKENHI grants 15H03732, 15H05815, $16 \mathrm{H} 02229$, and $18 \mathrm{H} 01254$

\section{References}

Ahn, B. H., Akasofu, S. I., \& Kamide, Y. (1983). The Joule heat production rate and the particle energy injection rate as a function of the geomagnetic indices AE and AL. Journal of Geophysical Research, 88(A8), 6275-6288. https://doi.org/10.1029/JA088iA08p06275

Akasofu, S. I. (1964). The development of the auroral substorm. Planetary and Space Science, 12(4), 273-282. https://doi. org/10.1016/0032-0633(64)90151-5

Akasofu, S. I. (1980). The solar wind-magnetosphere energy coupling and magnetospheric disturbances. Planetary and Space Science, 28(5), 495-509. https://doi.org/10.1016/0032-0633(80)90031-8

Akasofu, S. I., Chapman, S., \& Meng, C. I. (1965). The polar electrojet. Journal of Atmospheric and Terrestrial Physics, 27(11-12), 12751305. https://doi.org/10.1016/0021-9169(65)90087-5

Birn, J., \& Hesse, M. (2005). Energy release and conversion by reconnection in the magnetotail. Annales Geophysicae, 23(10), 3365-3373. https://doi.org/10.5194/angeo-23-3365-2005

Birn, J., \& Hesse, M. (2013). The substorm current wedge in MHD simulations. Journal of Geophysical Research: Space Physics, 118, 33643376. https://doi.org/10.1002/jgra.50187

Boteler, D. H., Pirjola, R. J., \& Nevanlinna, H. (1998). The effects of geomagnetic disturbances on electrical systems at the Earth's surface. Advances in Space Research, 22(1), 17-27. https://doi.org/10.1016/s0273-1177(97)01096-x

Cnossen, I., Richmond, A. D., \& Wiltberger, M. (2012). The dependence of the coupled magnetosphere-ionosphere-thermosphere system on the Earth's magnetic dipole moment. Journal of Geophysical Research, 117, A05302. https://doi.org/10.1029/2012ja017555

Cnossen, I., Richmond, A. D., Wiltberger, M., Wang, W., \& Schmitt, P. (2011). The response of the coupled magnetosphere-ionospherethermosphere system to a $25 \%$ reduction in the dipole moment of the Earth's magnetic field. Journal of Geophysical Research, 116, 12304. https://doi.org/10.1029/2011JA017063

Coxon, J. C., Milan, S. E., Clausen, L. B. N., Anderson, B. J., \& Korth, H. (2014). A superposed epoch analysis of the regions 1 and 2 Birkeland currents observed by AMPERE during substorms. Journal of Geophysical Research: Space Physics, 119, 9834-9846. https:// doi.org/10.1002/2014ja020500

Ebihara, Y., \& Tanaka, T. (2013). Fundamental properties of substorm time energetic electrons in the inner magnetosphere. Journal of Geophysical Research: Space Physics, 118, 1589-1603. https://doi.org/10.1002/jgra.50115

Ebihara, Y., Tanaka, T., \& Kikuchi, T. (2014). Counter equatorial electrojet and overshielding after substorm onset: Global MHD simulation.

study. Journal of Geophysical Research: Space Physics, 119(9), 7281-7296. https://doi.org/10.1002/2014ja020065

Ebihara, Y., \& Tanaka, T. (2015a). Substorm simulation: Formation of westward traveling surge. Journal of Geophysical Research: Space Physics, 120, 466-410. https://doi.org/10.1002/2015JA021697

Ebihara, Y., \& Tanaka, T. (2015b). Substorm simulation: Insight into the mechanisms of initial brightening. Journal of Geophysical Research: Space Physics, 120, 7270-7288. https://doi.org/10.1002/2015JA021516

Ebihara, Y., \& Tanaka, T. (2017). Energy flow exciting field-aligned current at substorm expansion onset. Journal of Geophysical Research: Space Physics, 122, 12288-12309. https://doi.org/10.1002/2017JA024294

Ebihara, Y., \& Tanaka, T. (2018). Why does substorm-associated auroral surge travel westward? Plasma Physics and Controlled Fusion, 60(1). https://doi.org/10.1088/1361-6587/aa89fd

Ebihara, Y., Tanaka, T., \& Kamiyoshikawa, N. (2019). New diagnosis for energy flow from solar wind to ionosphere during substorm: Global MHD simulation. Journal of Geophysical Research: Space Physics, 124, 360-378. https://doi.org/10.1029/2018JA026177

Garrett, H. B. (1981). The charging of spacecraft surfaces. Reviews of Geophysics, 19(4), 577-616. https://doi.org/10.1029/RG019i004p00577

Glassmeier, K. H., Vogt, J., Stadelmann, A., \& Buchert, S. (2004). Concerning long-term geomagnetic variations and space climatology. Annales Geophysicae, 22(10), 3669-3677. https://doi.org/10.5194/angeo-22-3669-2004

Gonzalez, W. D., \& Mozer, F. S. (1974). A quantitative model for the potential resulting from reconnection with an arbitrary interplanetary magnetic field. Journal of Geophysical Research, 79(28), 4186-4194. https://doi.org/10.1029/JA079i028p04186

Hayakawa, H., Ebihara, Y., Cliver, E. W., Hattori, K., Toriumi, S., Love, J. J., et al. (2019). The extreme space weather event in September 1909. Monthly Notices of the Royal Astronomical Society, 484(3), 4083-4099. https://doi.org/10.1093/mnras/sty3196

Hayakawa, H., Mitsuma, Y., Ebihara, Y., \& Miyake, F. (2019). The earliest candidates of auroral observations in Assyrian astrological reports: Insights on solar activity around 660 BCE. The Astrophysical Journal, 884(1). https://doi.org/10.3847/2041-8213/ab42e4

Iijima, T., \& Potemra, T. A. (1976). The amplitude distribution of field-aligned currents at northern high latitudes observed by Triad. Journal of Geophysical Research, 81(13), 2165-2174. https://doi.org/10.1029/JA081i013p02165

Kamide, Y., \& Akasofu, S. I. (1975). The auroral electrojet and global auroral features. Journal of Geophysical Research, 80(25), 3585-3602. https://doi.org/10.1029/ja080i025p03585

Kamide, Y., Craven, J. D., Frank, L. A., Ahn, B. h., \& Akasofu, S. I. (1986). Modeling substorm current systems using conductivity distributions inferred from DE auroral images. Journal of Geophysical Research, 91(A10), 11235-11256. https://doi.org/10.1029/ JA091iA10p11235

Kamide, Y., Sun, W., \& Akasofu, S. I. (1996). The average ionospheric electrodynamics for the different substorm phases. Journal of Geophysical Research, 101(A1), 99-109. https://doi.org/10.1029/95ja02990

Kan, J. R., Lee, L. C., \& Akasofu, S. I. (1980). The energy coupling function and the power generated by the solar wind-magnetosphere dynamo. Planetary and Space Science, 28(8), 823-825. https://doi.org/10.1016/0032-0633(80)90080-x

Kelley, M. C. (2009). The Earth's ionosphere (2nd ed.). Elsevier.

Knudsen, M. F., Riisager, P., Donadini, F., Snowball, I., Muscheler, R., Korhonen, K., \& Pesonen, L. J. (2008). Variations in the geomagnetic dipole moment during the Holocene and the past 50 kyr. Earth and Planetary Science Letters, 272(1-2), 319-329. https://doi. org/10.1016/j.epsl.2008.04.048

Lu, G., Richmond, A. D., Lühr, H., \& Paxton, L. (2016). High-latitude energy input and its impact on the thermosphere. Journal of Geophysical Research: Space Physics, 121, 7108-7124. https://doi.org/10.1002/2015ja022294 
McPherron, R. L. (1970). Growth phase of magnetospheric substorms. Journal of Geophysical Research, 75(28), 5592-5599. https://doi.org/10.1029/JA075i028p05592

Murphy, K. R., Mann, I. R., Rae, I. J., Waters, C. L., Frey, H. U., Kale, A., et al. (2013). The detailed spatial structure of field-aligned currents comprising the substorm current wedge. Journal of Geophysical Research: Space Physics, 118, 7714-7727. https://doi. org/10.1002/2013JA018979

Newell, P. T., \& Gjerloev, J. W. (2011a). Evaluation of SuperMAG auroral electrojet indices as indicators of substorms and auroral power. Journal of Geophysical Research, 116, A12211. https://doi.org/10.1029/2011JA016779

Newell, P. T., \& Gjerloev, J. W. (2011b). Substorm and magnetosphere characteristic scales inferred from the SuperMAG auroral electrojet indices. Journal of Geophysical Research, 116, A12232. https://doi.org/10.1029/2011JA016936

Obayashi, T., \& Nishida, A. (1968). Large-scale electric field in the magnetosphere. Space Science Reviews, 8(1), 3-31. https://doi. org $/ 10.1007 /$ bf00362569

Olson, P., \& Amit, H. (2006). Changes in Earth's dipole. Naturwissenschaften, 93(11), 519-542. https://doi.org/10.1007/s00114-006-0138-6

Palmroth, M., Janhunen, P., Pulkkinen, T. I., Aksnes, A., Lu, G., Østgaard, N., et al. (2005). Assessment of ionospheric Joule heating by GUMICS-4 MHD simulation, AMIE, and satellite-based statistics: Toward a synthesis. Annales Geophysicae, 23(6), 2051-2068. https:// doi.org/10.5194/angeo-23-2051-2005

Perreault, P., \& Akasofu, S. I. (1978). A study of geomagnetic storms. Geophysical Journal International, 54(3), 547-573. https://doi. org/10.1111/j.1365-246X.1978.tb05494.x

Pirjola, R., \& Viljanen, A. (1989). On geomagnetically-induced currents in the Finnish $400 \mathrm{kV}$ power system by an auroral electrojet current. IEEE Transactions on Power Delivery, 4(2), 1239-1245. https://doi.org/10.1109/61.25609

Richmond, A. D., Kamide, Y., Akasofu, S.-I., Alcaydé, D., Blanc, M., de la Beaujardière, O., et al. (1990). Global measures of ionospheric electrodynamic activity inferred from combined incoherent scatter radar and ground magnetometer observations. Journal of Geophysical Research, 95(A2), 1061-1071. https://doi.org/10.1029/JA095iA02p01061

Robinson, R. M., Vondrak, R. R., Craven, J. D., Frank, L. A., \& Miller, K. (1989). A comparison of ionospheric conductances and auroral luminosities observed simultaneously with the Chatanika Radar and the DE 1 auroral imagers. Journal of Geophysical Research, 94(A5), 5382-5396. https://doi.org/10.1029/JA094iA05p05382

Rosen, A. (1976). Spacecraft charging by magnetospheric plasmas. IEEE Transactions on Nuclear Science, 23(6), 1762-1768. https://doi. org/10.1109/TNS.1976.4328575

Rostoker, G., Akasofu, S. I., Foster, J., Greenwald, R. A., Kamide, Y., Kawasaki, K., et al. (1980). Magnetospheric substorms—Definition and signatures. Journal of Geophysical Research, 85(A4), 1663-1668. https://doi.org/10.1029/ja085ia04p01663

Siscoe, G. L., \& Chen, C. K. (1975). The paleomagnetosphere. Journal of Geophysical Research, 80(34), 4675-4680. https://doi.org/10.1029/ JA080i034p04675

Siscoe, G. L., \& Christopher, L. (1975). Effects of geomagnetic dipole variations on the auroral zone locations. Journal of Geomagnetism and Geoelectricity, 27(6), 485-489. https://doi.org/10.5636/jgg.27.485

Siscoe, G. L., \& Cummings, W. D. (1969). On the cause of geomagnetic bays. Planetary and Space Science, 17(10), 1795-1802. https://doi. org/10.1016/0032-0633(69)90055-5

Takeda, M. (1996). Effects of the strength of the geomagnetic main field strength on the dynamo action in the ionosphere. Journal of Geophysical Research, 101(A4), 7875-7880. https://doi.org/10.1029/95ja03807

Takeda, M. (2013). Contribution of wind, conductivity, and geomagnetic main field to the variation in the geomagnetic Sq field. Journal of Geophysical Research: Space Physics, 118, 4516-4522. https://doi.org/10.1002/jgra.50386

Tanaka, T. (2015). Substorm auroral dynamics reproduced by advanced global magnetosphere-ionosphere (M-I) coupling simulation. In Auroral dynamics and space weather (pp. 177-190). https://doi.org/10.1002/9781118978719.ch13

Tanaka, T., Ebihara, Y., Watanabe, M., Den, M., Fujita, S., Kikuchi, T., et al. (2017). Global simulation study for the time sequence of events leading to the substorm onset. Journal of Geophysical Research: Space Physics, 122, 6210-6239. https://doi.org/10.1002/2017JA024102

Tanaka, T., Nakamizo, A., Yoshikawa, A., Fujita, S., Shinagawa, H., Shimazu, H., et al. (2010). Substorm convection and current system deduced from the global simulation. Journal of Geophysical Research, 115, A05220. https://doi.org/10.1029/2009JA014676

Tanskanen, E., Pulkkinen, T. I., Koskinen, H. E. J., \& Slavin, J. A. (2002). Substorm energy budget during low and high solar activity: 1997 and 1999 compared. Journal of Geophysical Research, 107(A6), 1086. https://doi.org/10.1029/2001JA900153

Tao, C., Jin, H., Shinagawa, H., Fujiwara, H., \& Miyoshi, Y. (2017). Effect of intrinsic magnetic field decrease on the low- to middle-latitude upper atmosphere dynamics simulated by GAIA. Journal of Geophysical Research: Space Physics, 122, 9751-9762. https://doi. org/10.1002/2017ja024278

Tarduno, J. A., Cottrell, R. D., Watkeys, M. K., \& Bauch, D. (2007). Geomagnetic field strength 3.2 billion years ago recorded by single silicate crystals. Nature, 446(7136), 657-660. https://doi.org/10.1038/nature05667

Thébault, E., Finlay, C. C., Beggan, C. D., Alken, P., Aubert, J., Barrois, O., et al. (2015). International geomagnetic reference field: The 12th generation. Earth Planets and Space, 67(1). https://doi.org/10.1186/s40623-015-0228-9

Yao, Y., Ebihara, Y., \& Tanaka, T. (2015a). Formation and evolution of high-plasma-pressure region in the near-Earth plasma sheet: Precursor and postcursor of substorm expansion onset. Journal of Geophysical Research: Space Physics, 120, 6427-6435. https://doi. org/10.1002/2015JA021187

Yao, Y., Ebihara, Y., \& Tanaka, T. (2015b). Sudden pressure enhancement and tailward retreat in the near-Earth plasma sheet: THEMIS observation and MHD simulation. Journal of Geophysical Research: Space Physics, 120, 201-211. https://doi.org/10.1002/2014JA020482

Yokoyama, N., Kamide, Y., \& Miyaoka, H. (1998). The size of the auroral belt during magnetic storms. Annales Geophysicae, 16(5), 566-573 https://doi.org/10.1007/s005850050626

Zhou, X. Y., Sun, W., Ridley, A. J., \& Mende, S. B. (2011). Joule heating associated with auroral electrojets during magnetospheric substorms. Journal of Geophysical Research, 116, A10312. https://doi.org/10.1029/2010JA015804

Zieger, B., Vogt, J., \& Glassmeier, K. H. (2006a). Scaling relations in the paleomagnetosphere derived from MHD simulations. Journal of Geophysical Research, 111, A06203. https://doi.org/10.1029/2005JA011531

Zieger, B., Vogt, J., Ridley, A. J., \& Glassmeier, K. H. (2006b). A parametric study of magnetosphere-ionosphere coupling in the paleomagnetosphere. Advances in Space Research, 38(8), 1707-1712. https://doi.org/10.1016/j.asr.2005.04.077 